Quebec Cooperative Study

of Friedreich's Ataxia

\title{
The Beta-Amino Acid Transport System in Friedreich's Ataxia
}

\author{
S.B. MELANÇON, B. GRIGNON, E. LEDRU, G. GEOFFROY, M. POTIER, L. DALlAIRE and M. VANASSE
}

SUMMARY: Taurine and $\beta$-alanine uptake in cultured skin fibroblasts proceeds through at least two distinct amino acid transport systems. The predominant $\beta$ amino acid uptake system which we refer to as the "Beta" system, incorporates taurine in a proportion of $95 \%$. B-alanine in a proportion of $80 \%$ and does not incorporate $\beta$-amino-isobutyric acid. A second transport system for $\beta$-alanine seems to be operative in cultured skin fibroblasts and

RESUME: L'incorporation des acides $\beta$-aminés taurine et $\beta$-alanine dans les fibroblastes cutanés en culture s'opère par l'entremise de deux systèmes de transport majeurs, les systèmes "Beta" et " $L$ ". Le système "Beta" est responsable de l'incorporation de la taurine dans une porportion de $95 \%$ et de la $\beta$-alanine dans une proportion moindre, soit $80 \%$. Le reste de la $\beta$-alanine serait apparemment transporté par un système alterne, fortement apparenté au système " $L$ " déjà décrit pour le transport this system shares the characteristics of system " $L$ " for branched-chain and ringside neutral amino acids. Results of ion depletion experiments, metabolic inhibition by drugs and blocking agents and previous kinetic studies of taurine and $\beta$-alanine uptake in cultured skin fibroblasts failed to disclose any major difference in $\beta$-amino acid transport between control individuals and patients with Friedreich's ataxia.

des acides aminés neutres à chaîne ramifiée ou à chaine latérale. Nos études cinétiques antérieures et nos résultats présents, quant à la régulation métabolique du transport des acides $\beta$-aminés en culture de tissus, tendent à démontrer le fonctionnement normal des systèmes d'incorporation de la taurine et de la $\beta$-alanine dans les fibroblastes de patients atteints de l'Ataxie de Friedreich.
The $\beta$-amino acids taurine (Tau) and $\beta$-alanine (Bala) have been of little consideration to clinical investigators until the report by Scriver et al (1966) of a male infant with hyper- $\beta$ alaninemia, somnolence and seizures. Acquired abnormalities of urinary Bala excretion were later described in patients rejecting their kidney transplant (Gras et al, 1968) and patients afflicted with tuberculosis of various organs (Takao et al, 1968). Primary aberrations in taurine metabolism have yet to be identified in man. Increased urinary excretion of taurine has been reported in patients with familial cerebellar dyssynergia (Hall et al, 1974) and in a familial syndrome of camptodactyly and hypertaurinuria (Nevin et al, 1966). A specific defect in the $\beta$-amino acid transport system of mouse kidney has been described by Chesney et al (1976) but no such anomaly has been documented in human hypertaurinuria.

Our interest in $\beta$-amino acid transport in Friedreich's ataxia (F.A.) started with the observation of an apparent renal defect in the reabsorption of Tau (Filla et al, 1979) and Bala (Lemieux et al, 1976) in addition to uniformly elevated levels of Tau in various areas of the brain in two patients with F.A. (Huxtable et al, 1979). In a previous study, we compared the uptake kinetics of Tau and Bala using cultured skin fibroblasts from patients with F.A. and control individuals (Melançon et al, 1979a).

Michaelis-Menten constants $\left(\mathbf{K}_{\mathrm{m}}\right)$ and maximal uptake velocities $\left(\mathrm{V}_{\max }\right)$ of both Tau and Bala were found to be comparable between patients and controls, and in accordance with the values reported by Lombardini (1978) for other tissue culture systems. Furthermore, the kinetics of Tau 
uptake in fibroblasts were comparable with values reported for brain tissue (Cutler et al, 1978; Hruska et al, 1978a; Hruska et al, 1978b; Lombardini, 1978; Borg et al, 1979a and b; Martin and Shain 1979), heart (Huxtable and Chubb, 1977; Chubb and Huxtable 1978a and b), kidney (Chesney et al, 1978; Rozen et al, 1979; Hammerman and Sacktor, 1978) and blood platelets (Filla et al, 1978).

The present investigation intended to elucidate the regulatory mechanisms under Tau and Bala uptake using cultured skin fibroblasts from patients with F.A. and controls in order to rule out a possible dysfunction due to metabolic inhibition by ions, other amino acids or cellular energy blockers.

\section{MATERIALS AND METHODS}

Skin biopsies were obtained with informed consent from nine patients with F.A. and seventeen control subjects. Fibroblast cultures and amino acid uptake experiments were conducted as previously described (Melançon et al, 1979b) except for the following modifications: Fetal calf serum concentration was increased to $20 \%$ and no antibiotics were added to the nutrient mixture. All uptake experiments were done at $37^{\circ} \mathrm{C}$ using $1,2-14 \mathrm{C}$ Taurine or ${ }^{1-14} \mathrm{C} \quad \beta$-alanine (New England Nuclear; specific activity, $56.08 \mathrm{mCi} / \mathrm{mmole}$ for Tau and 55.19 $\mathrm{mCi} / \mathrm{mmole}$ for Bala) with added unlabelled Tau or Bala to give a final concentration of $30 \mu \mathrm{M}$. The ratio of labelled/unlabelled amino acids approximated $1 / 3$. Both radioactive and unlabelled Tau (Sigma Chem Co.) and Bala (Calbiochem Co.) were found to be chromatographically pure by twodimensional paper chromatography and autoradiography. The incubation medium consisted of $1 \mathrm{mM}$ tris (hydroxymethyl) aminomethane buffer (Fisher Scientific) pH 7.4, containing $0.1 \%$ glucose and the test compounds.

The effect of sodium depletion was studied using lithium chloride (MCB) and/or choline chloride (Sigma Chem Co.) instead of sodium chloride. Inhibition studies with membrane active compounds and drugs followed a $15 \mathrm{~min}$. pre-incubation period in trisbuffer containing the inhibitor at a concentration of $50 \mu \mathrm{M}$. At the end of the pre-incubation time, the cell- layered coverslips were transferred into a new bath containing the amino acid studied and the inhibitor. The following compounds were tested: chlorpromazine (CPZ), ouabain, $\mathrm{m}$ chlorocarbonyl-cyanide phenylhydrazone (CCCP), n-ethyl-maleimide (NEM), L-isoproterenol, DLpropanolol- $\mathrm{HCl}$, iodoacetate and dibutyryl-cyclic AMP (DBcAMP) from Sigma Chem. Co.; Potassium cyanide (KNC) from Fisher Co. and Insulin from Connaught Laboratories.

Amino acid competition studies were performed using the following competitive amino acids at a concentration of $1 \mathrm{mM}$ : L-alanine, L-leucine and hypotaurine from Calbiochem Co.; $\alpha$-methyl-amino-isobutyric acid $(\alpha$-MAIB), $\beta$-amino-isobutyric acid (BAIB) and homoarginine from Sigma Chem Co.; $\mathrm{N}$-methyl-taurine from ICN Pharmaceuticals Inc.; 2-aminobicyclo $(2,2$,$) heptane-2-carboxylic acid$ $(\mathrm{BCH})$ and 4-amino-1-guanyl-piperidine-4-carboxylic acid (GPA) were a generous gift of Prof. H.N. Christensen, University of Michigan, Ann Arbor, Michigan.

\section{RESULTS}

\section{B-amino acid uptake:}

The uptake of Tau and Bala by cultured skin fibroblasts of controls and patients with F.A. is illustrated in figure 1 . Tau uptake averaged $0.088 \pm$ $0.057 \mathrm{nmole} / \mathrm{min} / \mathrm{mg}$ protein in controls and $0.091 \pm 0.021$ in F.A. Mean Bala uptake was $0.067 \pm 0.012$ nmole $/ \mathrm{min} / \mathrm{mg}$ protein in controls and $0.077 \pm 0.020$ in F.A. These values were not statistically different. All individual Tau uptake values in F.A. fibroblasts were within the range of control values. Two control lines of fibroblasts derived from presumed heterozygotes for Duchenne muscular dystrophy averaged Tau uptake values above one standard deviation from the mean. Bala uptake values in controls were more clustered than Tau uptake values and two patients with F.A. had Bala uptake values above the control range.

\section{Ion dependency:}

The uptake of Tau and Bala by cultured skin fibroblasts of controls and patients with F.A. demonstrated comparable sodium $>$ calcium $>$ potassium dependency and magnesium inhibition (table 1). While close to $25 \%$ of Bala uptake occurred without sodium, almost no Tau uptake took place under the same conditions.

\section{Metabolic inhibitors:}

F.A. and control fibroblasts were similarly affected by all metabolic inhibitors tested (table 2). Tau uptake was selectively more inhibited than Bala uptake by ion exchange blockers (CPZ, ouabain, CCCP) and by respiratory chain $(\mathrm{KCN})$, sulfhydryl (NEM) and glycolysis (iodoacetate) inhibitors. The other compounds displayed little effect on $\beta$-amino acid uptake, with the exception of isoproterenol (slight

TABLE 1

Ion Dependency of B-Amino Acid Uptake In Cultured Human Skin Fibroblasts

\begin{tabular}{l|cc|cc}
\hline \multirow{2}{*}{ Missing Ion: } & \multicolumn{4}{c}{ \% Uptake (Mean \pm S.D.): } \\
\cline { 2 - 5 } & \multicolumn{2}{|c|}{ Taurine: } & \multicolumn{2}{c}{$\beta$-Alanine: } \\
\cline { 2 - 5 } & controls* $^{*}$ F.A.** & 100 & 100 \\
\hline None & 100 & 100 & $27 \pm 19$ & $17 \pm 13$ \\
Sodium & $4 \pm 7$ & $2 \pm 3$ & $27 \pm 23$ & $18 \pm 14$ \\
Sodium +Lithium & $8 \pm 11$ & $7 \pm 10$ & $73 \pm 33$ & $75 \pm 26$ \\
Calcium & $65 \pm 25$ & $64 \pm 16$ & $88 \pm 30$ & $92 \pm 18$ \\
Potassium & $81 \pm 38$ & $71 \pm 25$ & $112 \pm 26$ & $132 \pm 40$ \\
Magnesium & $110 \pm 23$ & $116 \pm 24$ & & \\
\hline
\end{tabular}

*: Ten cell lines studied in duplicate

**: Five cell lines studied in duplicate 
inhibition) and insulin (slight stimulation).

\section{Effect of other amino acids:}

Although the small number of cell lines studied did not permit adequate statistical analysis, Tau and Bala uptake by F.A. and control fibroblasts was comparably affected by competitive amino acids (table 3). Tau and Bala were inhibitory to each other. Close analogues such as hypotaurine and $\mathrm{N}$-methyl-taurine also displayed inhibition, hypotaurine being more competitive for Tau and N-methyltaurine predominantly affecting Bala uptake. Another closely related $\beta$ amino acid BAIB did not markedly affect Tau nor Bala uptake in fibroblasts. While displaying no competition with Tau, both leucine and $\mathrm{BCH}$, characteristic substrates of transport system " $L$ " and both alanine and $\alpha$-MAIB, characteristic substrates of transport system " $A$ ", inhibited Bala uptake by approximately 20 to $30 \%$. Homoarginine and GPA, characteristic substrates of transport system " $L y "$ " had no competitive effect on the uptake of either Tau or Bala.

\section{DISCUSSION}

These results support our previous data on the kinetics of $\beta$-amino acid uptake (Melançon et al, 1979a) and confirm that Tau and Bala are normally transported in cultured skin fibroblasts of patients with F.A. The apparent discrepancy between urinary findings (Lemieux et al, 1976; Filla et al, 1979) and our fibroblast studies can be explained in many ways. First, the $\beta$-amino acid uptake system in fibroblasts may be different from the tubular transport system in kidney. Second, tubular reabsorption of Tau and Bala may be impaired as a primary defect which is not expressed in tissues other than kidney, or as a secondary phenomenon which is corrected by tissue culture conditions. Finally, the increased urinary output of Tau and Bala in patients with F.A. may reflect an increased filtered load of $\beta$-amino acids from poor muscle reserve pools, without any alteration in the tubular reabsorptive process.

Our data suggest that cultured skin fibroblasts incorporate Tau and Bala via two distinct amino acid transport systems (fig. 2). System "Beta" operates through an electrochemical gradient of sodium and actively incorporates Tau in a proportion of $95 \%$ and Bala in a proportion of $80 \%$. These figures come from both sodium depletion (table 1) and $\mathrm{Na}^{+} / \mathrm{K}^{+}$ATPase inhibition (table 2) experiments. System "Beta" is specific for the $\beta$-amino acids with the

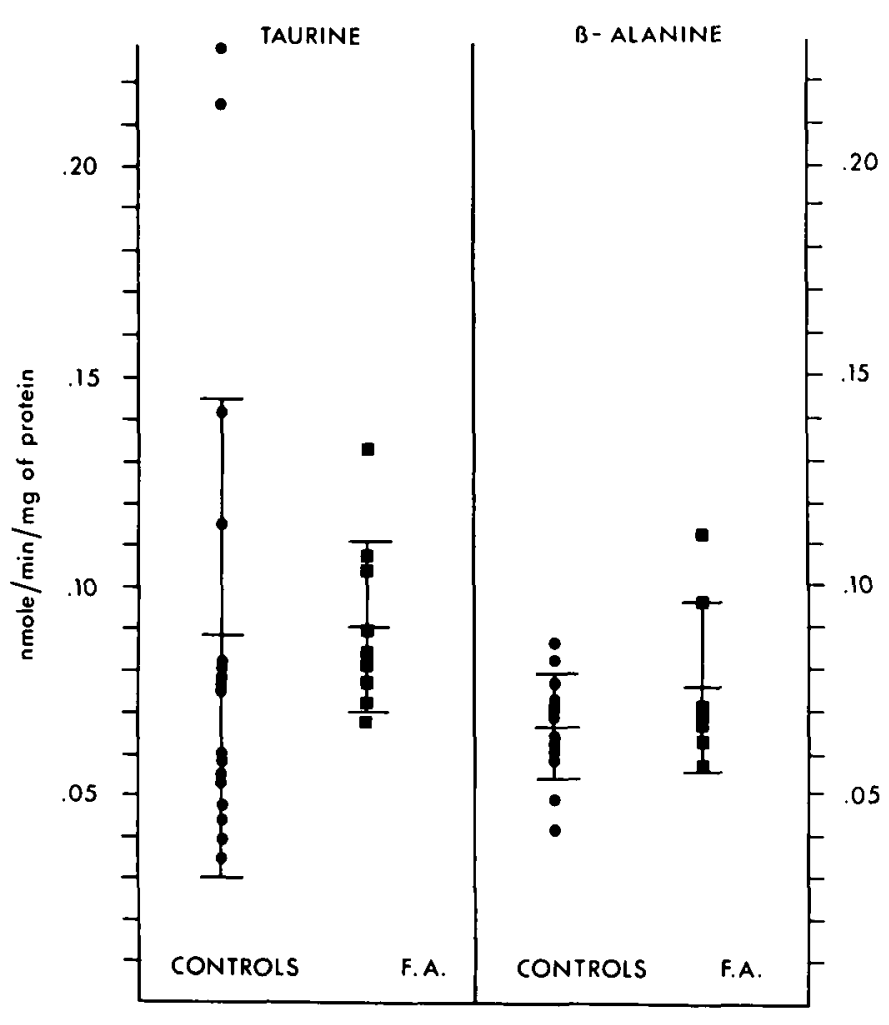

Figure $1-$ Mean $\beta$-amino acid uptake values in cultured human skin fibroblasts from patients with Friedreich's Ataxia and control individuals. The horizontal lines represent the mean and standard deviation from the mean.

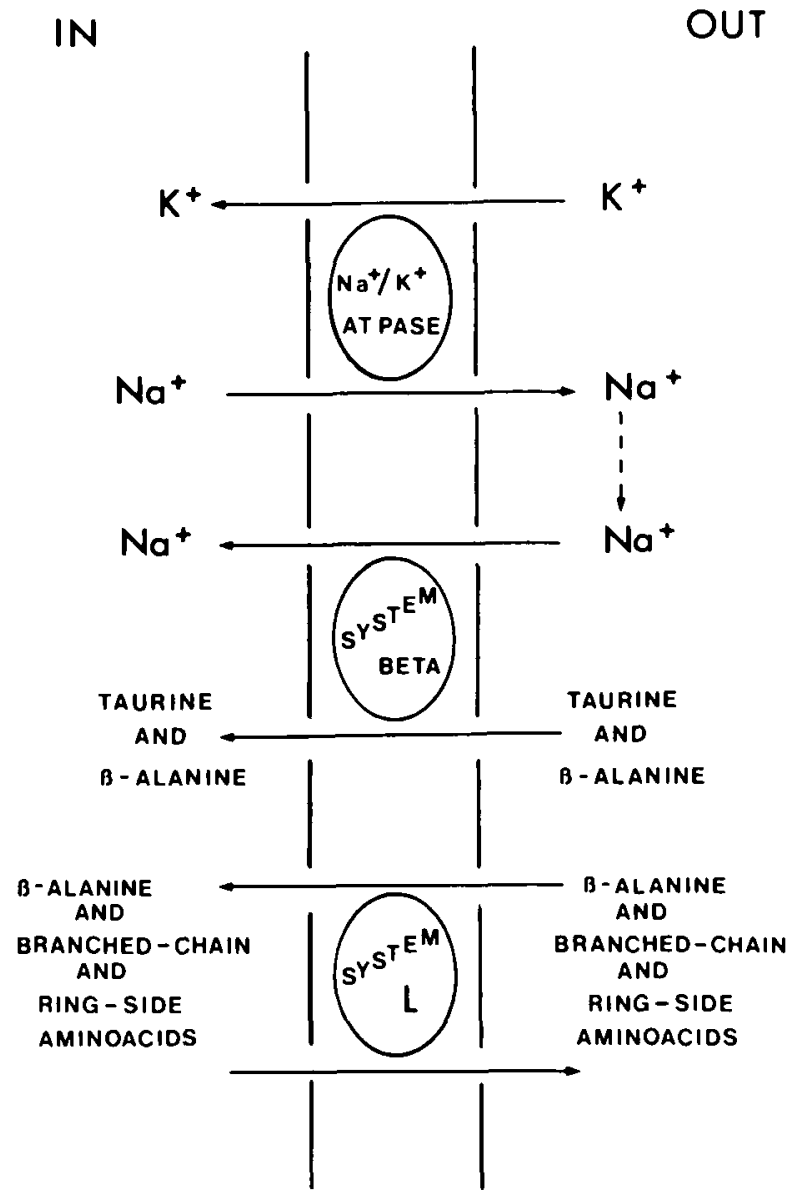

Figure 2 - Schematic diagram showing the mechanisms involved in active uptake of Taurine and $\beta$-alanine in cultured human skin fibroblasts. 
TABLE 2

Metabolic Inhibitors of $\beta$-Amino Acid Uptake In Cultured Human Skin Fibroblasts

\begin{tabular}{l|cc|cc}
\hline \multirow{2}{*}{$\begin{array}{l}\text { Inhibitor } \\
(50 \mu \mathbf{M})\end{array}$} & \multicolumn{3}{c}{$\%$ Uptake (Mean \pm S.D.): } \\
\cline { 2 - 5 } & \multicolumn{3}{|c|}{ Taurine $(\mathbf{3 0} \mu \mathbf{M}):$} & \multicolumn{1}{c}{$\beta$-Alanine (30 $\mu$ M): } \\
\cline { 2 - 5 } & controls* & F.A.* & \multicolumn{1}{c}{ controls** } & F.A.*** \\
\hline None & 100 & 100 & 100 & 100 \\
CPZ & $11 \pm 5$ & $12 \pm 1$ & $25 \pm 6$ & $24 \pm 6$ \\
Ouabain & $48 \pm 12$ & $53 \pm 9$ & $81 \pm 14$ & $90 \pm 28$ \\
CCCP & $48 \pm 5$ & $50 \pm 11$ & $52 \pm 2$ & $59 \pm 20$ \\
KCN & $65 \pm 8$ & $54 \pm 8$ & $85 \pm 4$ & $76 \pm 9$ \\
NEM & $65 \pm 25$ & $68 \pm 15$ & $108 \pm 20$ & $107 \pm 15$ \\
Iodoacetate & $83 \pm 8$ & $86 \pm 8$ & $127 \pm 4$ & $131 \pm 24$ \\
Isoprotenerol & $81 \pm 9$ & $86 \pm 27$ & $72 \pm 25$ & $85 \pm 17$ \\
Propanolol & $89 \pm 11$ & $93 \pm 22$ & $101 \pm 16$ & $120 \pm 36$ \\
DBcAMP & $98 \pm 17$ & $106 \pm 14$ & $103 \pm 8$ & $112 \pm 38$ \\
Insulin & $104 \pm 20$ & $118 \pm 15$ & $111 \pm 32$ & $112 \pm 40$ \\
\hline
\end{tabular}

*: Five cell lines studied in duplicate

**: Two cell lines studied in quadruplicate

***: Three cell lines studied in quadruplicate

TABLE 3

Influence Of Other Amino Acids On The Uptake Of Taurine And Beta-Alanine In Cultured Human Skin Fibroblasts

\begin{tabular}{l|cc|cc}
\hline \multirow{2}{*}{$\begin{array}{l}\text { Amino Acid } \\
(1 \mathrm{mM})\end{array}$} & \multicolumn{4}{c}{$\%$ Uptake (Mean \pm S.D.): } \\
\cline { 2 - 5 } & \multicolumn{2}{|c|}{ Taurine $(\mathbf{3 0} \mu \mathbf{M})$} & \multicolumn{1}{c}{$\beta$-Alanine $(30 \mu \mathbf{M})$} \\
\cline { 2 - 5 } None & controls* & F.A.** & controls* & F.A.** \\
Taurine & 100 & 100 & 100 & 100 \\
$\beta$-Alanine & - & - & $17 \pm 3$ & $17 \pm 1$ \\
Hypotaurine & $19 \pm 14$ & $21 \pm 1$ & - & - \\
N-methyl-taurine & $11 \pm 4$ & $7 \pm 0$ & $23 \pm 9$ & $21 \pm 2$ \\
BAIB & $64 \pm 7^{* *}$ & $71 \pm 4$ & $35 \pm 9$ & $54 \pm 3$ \\
L-leucine & $111 \pm 22^{* *}$ & $104 \pm 15$ & $74 \pm 3$ & $94 \pm 3$ \\
BCH & $92 \pm 17$ & $109 \pm 24$ & $66 \pm 10$ & $83 \pm 18$ \\
L-alanine & $118 \pm 7$ & $113 \pm 4$ & $56 \pm 19$ & $80 \pm 11$ \\
$\alpha$-MAIB & $95 \pm 15^{* *}$ & $77 \pm 14$ & $65 \pm 5$ & $81 \pm 2$ \\
Homoarginine & $91 \pm 23$ & $100 \pm 20$ & $70 \pm 13$ & $85 \pm 7$ \\
GPA & $118 \pm 1^{* *}$ & $102 \pm 6$ & $74 \pm 14$ & $112 \pm 11$ \\
\hline
\end{tabular}

*: Three cell lines studied in duplicate

**: Two cell lines studied in duplicate

exception of $\beta$-amino-isobutyric acid (table 3). A second transport system is responsible for the uptake of $\beta$-alanine in a proportion of approximately $20 \%$ (fig. 2). This system is not sodium dependent (table 1) and not affected by metabolic inhibitors (table 2). These properties and the competitive effect of leucine and $\mathrm{BCH}$ on Bala uptake would support the utilization of transport system "L" (Guidotti et al, 1978) by Bala as well as other branched-chain and ring-side amino acids. Beta-amino-isobutyric acid would seem to be incorporated into cultured skin fibroblasts through a third and as yet unknown transport system unrelated to system "Beta" and "L". Our previously reported data on the kinetics of Tau and Bala uptake in cultured skin fibroblasts (Melançon et al, 1979a) would then be valid only for Tau as this $\beta$-amino acid is incorporated through a single transport system in fibroblasts. The observed $\mathrm{Km}$ and Vmax for Bala uptake included Bala transport via systems "Beta" and "L" together in a proportion of four to one and these figures should probably be examined again. However, we assume from what is known about system " $\mathrm{L}$ " (Guidotti et al, 1978) that branchedchain amino acid metabolism in F.A. would have been initially more affected than Bala metabolism and this was not the case (Lemieux et al, 1976).

A major difference between the "Beta" amino acid transport system of cultured skin fibroblasts and mammalian kidney arises from competition studies with other $\beta$-amino acids. In fibroblasts (table 3 ) BAIB does not compete with Tau nor Bala while in kidney (Chesney et al, 1978, 1979a, 1979b, 1979c; Rozen et al, 1979; Hammerman et al, 1978) BAIB is a strong competitor of Tau uptake. In rat kidney cortex slices, Chesney et al (1978; 1979b) completely abolished Tau uptake using only ten times more concentrated BAIB. Rozen et al (1979) reached a $20 \%$ reduction in Tau uptake by renal brush-border membrane vesicles using BAIB at one hundred times the concentration of Tau. In fibroblasts, we have used a BAIB/Tau concentration ratio of $30 / 1$ without apparent effect (table 3). Furthermore, Rozen et al (1979) observed a reduction in Tau uptake when some $\alpha$-amino acids (alanine: $75 \%$; proline: $70 \%$ ) were added to the incubation mixture of brush-border membrane vesicles. No such competition of Tau uptake was observed with alanine using our preparation of cultured skin fibroblasts (table 3).

Many authors (Chubb and Huxtable, 1978a, 1978b, 1978c; Huxtable et al, 1977; Azari and Huxtable, 1980) have 
demonstrated the stimulating effect of isoproterenol, a $\beta$-adrenergic agonist, on Tau and Bala uptake in mammalian heart. Chubb et al (1978a) and Huxtable et al (1977) have also reported a comparable stimulation of Tau uptake by DBcAMP. We have not been able to reproduce these results with isoproterenol (20\% inhibition) and DBcAMR (0 to $12 \%$ stimulation only) using skin fibroblasts, but have found that all other Tau uptake characteristics reported in heart seem to apply to cultured skin fibroblasts.

In the central nervous system, Tau uptake proceeds differently whether glial or neuronal-type cell preparations are studied (Hruska et al, 1978a, 1978b; Martin et al, 1979; Lombardini, 1978). Borg et al (1979b) have demonstrated that glial cells in culture incorporate Tau better in the presence of calcium while neuronal cells do not totally depend on calcium for Tau uptake. This particularity of glial cells is comparable to the calcium-dependency of Tau uptake observed in our fibroblast studies (table 2).

In conclusion, we believe that Tau and Bala uptake in cultured skin fibroblasts proceeds through $\beta$-amino acid transport systems comparable if not identifical with heart and CNS glial cells. The $\beta$-amino acid transport systems "Beta" and "L") of fibroblast differ from kidney as they do not tolerate BAIB and other $\alpha$-amino acids. Finally, the observation that cultured skin fibroblast from patients with F.A. have a normal $\beta$-amino acid uptake system could imply that transport of Tau occurs normally in heart and glial cells also. The possibility remains that patients with F.A. are affected with a primary or secondary defect in renal handling of $\beta$-amino acids but such a defect would not seem to be a generalized membrane transport defect in F.A.

\section{ACKNOWLEDGEMENTS}

\footnotetext{
These studies were supported by the Medical Research Council of Canada, the Muscular Dystrophy Foundation and l'Association Canadienne de l'Ataxie de Friedreich. We thank Dr. H.N. Christensen, A. Barbeau, J.P. Bouchard and B. Lemieux for their cooperation in obtaining material and Misses D. Bernard, and $S$. Beaulieu for their help in preparing this manuscript.
}

\section{REFERENCES}

AZARI, J, and HUXTABLE, R.J. (1980). The mechanism of the adrenergic stimulation of taurine influx in the heart. Eruop. J. Pharmacol. 61: 217-223.

BORG, J. BALCAR, V.J. and MANDEL, P. (1979a). Effect of cyclic nucleotides on high affinity uptake of L-glutamate and taurine in glial and neuroblastoma cells. Brain Res. $166,113-120$.

BORG, J., BALCAR, V.J., MARK, J. and MANDEL, P. (1979b). Characterization of taurine uptake by neuronal and glial cells in culture. J. of Neurochem. 32: 1801-1805.

CHESNEY, R.W., SCRIVER, C.R. and MOHYUDDIN, F. (1976). Localization of membrane defect in transepithelial transport of taurine by parallel studies in vivo and in vitro in hypertaurinemic mice. J. Clin. Invest. 57: 183-193.

CHESNEY, R.W., JAX, D.K., SCRIVER, C.R. and MOHYUDDIN, F. (1978). Taurine transport in mammalian kidney. In taurine and neurological disorders, Editors: A. Barbeau and R.J. Huxtable, Raven Press pp. 73-93.

CHESNEY, R.W. and JAX, D.K. (1979a). Developmental aspects of renal $\beta$-amino acid transport. I. Ontogeny of taurine reabsorption and accumulation in rat renal cortex. Pediat. Res. 13: 854-860.

CHESNEY, R.W. and JAX, D.K. (1979b). Developmental aspects of renal $\beta$-amino acid transport 11. Ontogeny of uptake and efflux processes and effect of anoxia. Pediat. Res. 13: 861-867.

CHESNEY, R.W. and JAX, D.K. (1979c). The influence of glutathione oxidation on renal cortex taurine transport. Life Sciences 25: 1497-1506.

CHUBB, J. and HUXTABLE, R. (1978a). Isoproterenol-stimulated taurine influx in the perfused rat heart. Europ. J. Pharmacol. 48: 369-376.

CHUBB, J. and HUXTABLE, R. (1978b). The effects of Isoproterenol on taurine concentration in the rat heart. Europ. J. Pharmacol. 48: 357-367.

CHUBB, J. and HUXTABLE, R.J. (1978c). Transport and biosynthesis of taurine in the stressed heart. In taurine and neurological disorders. Editors: A. Barbeau and R.J. Huxtable, Raven Press pp. 161-178.

CUTLER, R.W.P. and COULL, B.M. (1978). Amino acid transport in brain. In: Taurine and neurological disorders. Editors: A. Barbeau and R.J. Huxtable, Raven Press pp. 95 à 107.

FILLA, A., BUTTERWORTH, R.F., GEOFFROY, G., LEMIEUX, B. and BARBEAU, A. (1978). Platelet taurine uptake in spinocerebellar degeneration. Can. J. Neurol. Sci. 5: 119-123.

FILLA, A., BUTTERWORTH, R.F. and BARBEAU, A. (1979). Pilot studies on membranes and some transport mechanisms in Friedreich's Ataxia. Can. J. Neurol. Sci. 3: 389-397.

GRAS, J., TUSET, N., CARALPS, A., GIL-
VERNET, J.M., MAGRINA, H., BRULLES, A. and CONDE, M. (1968). $\beta$-alaninuria following human renal allotransplantation. Clin. Chim. Acta 20: 295-298.

GUIDOTTI, G.G., BORGHETTI, A.F. and GAZZOLA, G.C. (1978). The regulation of amino acid transport in animal cells. Biochim. Biophys. Acta 515: 329-366.

HALL, C.D., STOWE, F.R. and SUMMER, G.K. (1974). Familial cerebellar dyssynergia and myoclonus epilepsy associated with defect of a mino acid metabolism. Neurology 24: 375 .

HAMMERMAN, M. and SACKTOR, B. (1978). Transport of $\beta$-alanine in renal brush border membrane vesicles. Biochim. Biophys. Acta 509: 338-347.

HRUSKA, R.E., HUXTABLE, R.J. and YAMAMURA, H.I. (1978a). High-affinity, temperature-sensitive and sodium-dependent transport of taurine in Rat brain. In taurine and neurological disorders. Editors A. Barbeau and R.J. Huxtable. Raven Press pp. 109-117.

HRUSKA, R.E., PADJEN, A., BRESSLER, R. and YAMAMURA, H.I. (1978b). Taurine sodium-dependent, high affinity transport into rat brain synaptosomes. Molec. Pharmacol. 14: 77-85.

HUXTABLE, R.J. and CHUBB, J. (1977). Adrenergic stimulation of taurine transport by the heart. Science 198: 409-4II.

HUXTABLE, R., AZARI, J., REISINE, T., JOHNSON, P., YAMAMURA, H.I. and BARBEAU, A. (1979). Regional distribution of amino-acids in Friedreich's Ataxia brains. Can. J. Neurol. Sci. 6: 255-259.

LEMIEUX, B., BARBEAU, A., BERONIADE, V., SHAPCOTT, D., BRETON, G., GEOFFROY, G. and MELANÇON, S.B. (1976). Amino acid metabolism in Friedreich's Ataxia. Can. J. Neurol. Sci. 3: 373-378.

LOMBARDINI, J.B. (1978). High-affinity transport of taurine in the mammalian central nervous system. In taurine and neurological disorders. Editors: A. Barbeau and R.J. Huxtable, Raven Press pp. 119-135.

MARTIN, D.L. and SHAIN, W. (1979). Highaffinity transport of taurine and $\beta$-alanine and low affinity transport of $\gamma$-aminobutyric acid by a single transport system in cultured glioma cells. J. Biol. Chem. 254: (15): 70767084.

MELANCON, S.B., GRIGNON, B., POTIER, M. and DALLAIRE, L. (1979a). Taurine and $\beta$-alanine uptake in cultured human skin fibroblasts from patient with Friedreich's Ataxia. Can. J. Neurol. Sci. 6: 251-253.

MELANÇON, S.B., GRENIER, B., DALLAIRE, L., POTIER, M., FONTAINE, G., GRIGNON, B., GEOFFROY, G., LEMIEUX, $B$. and BARBEAU, A. (1979b). Dicarboxylic amino acid uptake in normal, Friedreich's Ataxia and dicarboxylic aminoaciduria fibroblasts. Can. J. Neurol. Sci. 6: 263-275.

NEVIN, N.C., HURWITZ, L.J. and NEILL, D.W. (1966). Familial camptodactyly with taurinuria. J. Med. Genet. 3: 265-268.

ROZEN, R., TENENHOUSE, H.S. and 
SCRIVER, C.R. (1979). Taurine transport in renal brush-border-membrane vesicles. Biochem. J. 180: 245-248.

SCRIVER, C.R., PUESCHEL, S. and DAVIES,
E. (1966). Hyper- $\beta$-alaninemia associated with $\beta$-aminoaciduria and $\gamma$-aminobutyric aciduria, somnolence and seizures. New Engl. J. Med. 274: 636-643.
TAKAO, T., YASUMITSU, T., VOZUMI, T., KAKIMOTO, Y. and KANAZAWA, A. (1968). $\beta$-alaninuria in patients with tuberculosis. Nature (London) 217: 365-366. 